\title{
Predictors of survival in octogenarians after mitral valve surgery for degenerative disease: The Mitral Surgery in Octogenarians study
}

Pierpaolo Chivasso, MD, ${ }^{a}$ Vito D. Bruno, MD, PhD, ${ }^{a}$ Shakil Farid, MBBS, FRCS (C-Th), MBA, ${ }^{\mathrm{b}}$ Pietro Giorgio Malvindi, MD, PhD, ${ }^{\mathrm{c}}$ Amit Modi, MBBS, FRCS (C-Th), ${ }^{\mathrm{c}}$ Umberto Benedetto, $\mathrm{MD}, \mathrm{PhD},{ }^{\mathrm{a}}$ Franco Ciulli, MD, ${ }^{a}$ Yasir Abu-Omar, PhD, FRCS (C-Th), ${ }^{b}$ Massimo Caputo, MD, Mch, FRCS (C-Th), ${ }^{a}$ Gianni D. Angelini, MD, MCh, FRCS (C-Th), FMedSci, ${ }^{a}$ Steve Livesey, MD, FRCS (C-Th), ${ }^{\mathrm{c}}$ and Hunaid A. Vohra, MD, PhD, FRCS (C-Th) ${ }^{\mathrm{a}}$

\section{ABSTRACT}

Objectives: An increasing number of octogenarians are referred to undergo mitral valve surgery for degenerative disease, and percutaneous approaches are being increasingly used in this subgroup of patients. We sought to determine the survival and its predictors after Mitral Valve Surgery in Octogenarians (MiSO) in a multicenter UK study of high-volume specialized centers.

Methods: Pooled data from 3 centers were collected retrospectively. To identify the predictors of short-term composite outcome of 30 days mortality, acute kidney injury, and cerebrovascular accident, a multivariable logistic regression model was developed. Multiple Cox regression analysis was performed for late mortality. Kaplan-Meier curves were generated for long-term survival in various subsets of patients. Receiver operating characteristic analysis was done to determine the predictive power of the logistic European System for Cardiac Operative Risk Evaluation.

Results: A total of 247 patients were included in the study. The median follow-up was 2.9 years (minimum 0, maximum 14 years). A total of 150 patients $(60.7 \%)$ underwent mitral valve repair, and 97 patients (39.3\%) underwent mitral valve replacement. Apart from redo cardiac surgery (mitral valve repair 6 [4\%] vs mitral valve replacement $11[11.3 \%], P=.04$ ) and preoperative atrial fibrillation (mitral valve repair 79 [52.6\%] vs mitral valve replacement 34 [35.1\%], $P<.01$ ), there was no significant difference in terms of any other preoperative characteristics between the 2 groups. Patient operative risk, as estimated by logistic European System for Cardiac Operative Risk Evaluation, was lower in the mitral valve repair group $(10.2 \pm 11.8$ vs $13.7 \pm 15.2$ in mitral valve replacement; $P=.07)$. No difference was found between groups for duration of cardiopulmonary bypass and aortic crossclamp times. The 30-day mortality for the whole cohort was $13.8 \%$ (mitral valve repair $4.7 \%$ vs mitral valve replacement $18.6 \% ; P<.01)$. No differences were found in terms of postoperative cerebrovascular accident $(2 \%$ vs $3.1 \% ; P=.9)$, acute kidney injury requiring dialysis $(6.7 \%$ vs $13.4 \% ; P=.12)$, and superficial or deep sternal wound infection $(10 \%$ vs $16.5 \%, P=.17 ; 2 \%$ vs $3.1 \%, P=.67$, respectively). The final multiple regression model for short-term composite outcome included previous cardiac surgery

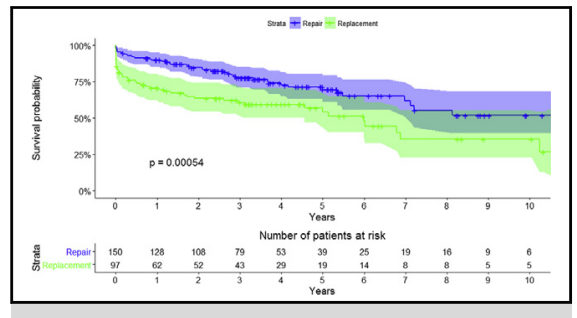

Kaplan-Meier survival curves between the 2 groups (raw data).

\section{Central Message}

In octogenarians, MVr demonstrated good inhospital outcomes and provided better survival compared with MVR.

\section{Perspective}

An increasing number of octogenarians are undergoing valve surgery, and there is a large body of evidence showing that octogenarians derive benefit from cardiac surgery. We demonstrated that MVr is safe and effective even in elderly patients, providing better short-term outcomes and long-term survival compared with MVR.

See Editorial Commentary page 1483.

See Editorial page 1461.
From the ${ }^{a}$ University Hospitals Bristol, Bristol Heart Institute, Bristol, United Kingdom; ' ${ }^{\mathrm{U}}$ University Hospitals Cambridge, Papworth Hospital, Cambridge, United Kingdom; and ${ }^{\mathrm{c}}$ University Hospitals Southampton, Wessex Cardiothoracic Centre, Southampton, United Kingdom.

This study was supported by the British Heart Foundation and the NIHR Bristol Cardiovascular Biomedical Research Centre.

Drs Chivasso and Bruno contributed equally to this work.

Read as an e-poster at the American Association for Thoracic Surgery Mitral Conclave, New York, New York, April 27-28, 2017.
Received for publication May 23, 2017; revisions received Oct 25, 2017; accepted for publication Nov 12, 2017; available ahead of print Dec 15, 2017.

Address for reprints: Pierpaolo Chivasso, MD, University Hospitals Bristol, Bristol Heart Institute Upper Maudlin St, BS2 8HW, Bristol, United Kingdom (E-mail: pierpaolochivasso@icloud.com).

0022-5223

Copyright (C) 2017 by The American Association for Thoracic Surgery. This is an open access article under the CC BY license (http://creativecommons.org/licenses/ by/4.0/).

https://doi.org/10.1016/j.jtcvs.2017.11.027 


\section{Abbreviations and Acronyms}
AKI
$=$ acute kidney injury
BMI
$=$ body mass index
CI
$=$ confidence interval
COPD $=$ chronic obstructive pulmonary disease
euroSCORE $=$ European System for Cardiac Operative Risk Evaluation
HR = hazard ratio
IABP $=$ intra-aortic balloon pump
LVEF = left ventricular ejection fraction
MiSO = Mitral Valve Surgery in
Octogenarians
MR $=$ mitral regurgitation
$\mathrm{MVr} \quad=$ mitral valve repair
MVR $=$ mitral valve replacement
OR $=$ odds ratio

\section{Scanning this $Q R$ code will take you to the supplemental tables and figure for this article.}

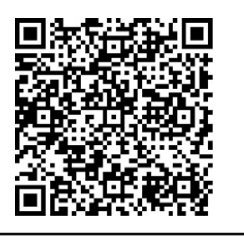

(odds ratio [OR], 4.47; 95\% confidence interval [CI], 1.37$17.46 ; P=.02$ ), intra-aortic balloon pump use (OR, 4.77; 95\% CI, 1.67-15.79; $P<.01$ ), and mitral valve replacement (OR, 7.7; 95\% CI, 4.04-14.9; $P<.01$ ). Overall survival for the entire cohort at 1,5 , and 10 years was $82.4 \%, 63.7 \%$, and $45.5 \%$ (mitral valve repair vs mitral valve replacement: $89.9 \%$ vs $70.7 \%$ at 1 year, $69.6 \%$ vs $54 \%$ at 5 years, and $51.8 \%$ vs $35.5 \%$ at 10 years; $P=.0005$ ). Cox proportional hazard model results showed mitral valve replacement (hazard ratio, $1.88 ; 95 \% \mathrm{CI}, 1.22-2.89 ; P<.01)$ and intra-aortic balloon pump use (hazard ratio, 2.54; 95\% CI, 1.26-5.13; $P<.01)$ to be independent predictor factors affecting long-term survival. Logistic European System for Cardiac Operative Risk Evaluation did not perform well in predicting early mortality (area under the curve, $0.57 \%$ ).

Conclusions: In octogenarians, mitral valve repair for degenerative disease is associated with good survival and remains the gold standard, whereas mitral valve replacement is still associated with significant mortality. Logistic European System for Cardiac Operative Risk Evaluation was unable to predict early mortality in our cohort of patients. Larger international multicenter registries are required to optimize the decision-making process in such a high-risk subgroup. (J Thorac Cardiovasc Surg 2018;155:1474-82)
In the past 2 decades, the definition of the "elderly" population in the cardiology literature has evolved: initially age more than 70 years, then more than 75 years, and now more than 80 years. ${ }^{1,2}$ The expectancy and quality of life of the elderly population continue to increase at the cost of a growing prevalence of cardiovascular conditions,${ }^{1-4}$ such as mitral valve disease. Thus, an increasing number of octogenarians are referred to undergo cardiac surgical procedures. ${ }^{4}$ Mitral valve repair (MVr) is the treatment of choice for severe mitral regurgitation (MR) in the general population, because it has been shown to provide a significant survival benefit over both medical treatment and mitral valve replacement (MVR). ${ }^{5-11}$ However, the feasibility and efficacy of mitral repair in very elderly patients are more controversial. ${ }^{12}$ Overall, there is a large body of evidence showing that octogenarians derive benefit from cardiac surgery. ${ }^{13-26}$ In the last decade, several studies have shown that cardiac surgical procedures performed in elderly patients, in otherwise good physical and mental health, can improve their mortality, morbidity, and quality of life.

Transcatheter mitral technologies are emerging as a viable option to treat high-risk and inoperable patients with mitral valve disease. ${ }^{27-32}$ These have shown promising early outcomes, especially in terms of procedural safety, and have being increasingly used in otherwise fit octogenarians requiring intervention for degenerative mitral valve disease. To this end, a clear understanding of the risks and benefits of mitral surgery in octogenarians in the current era is needed for rational decision-making regarding the best management option in this cohort of patients.

The purpose of this study was to determine the survival and determinants of its predictors after surgical MVr and MVR in octogenarians in a multicenter UK study, Mitral Valve Surgery in Octogenarians (MiSO), of high-volume specialist centers in the MitraClip (Abbott Vascular, Inc, Menlo Park, Calif) era.

\section{PATIENTS AND METHODS}

\section{Study Population and Definitions}

MiSO is a multicenter, retrospective, observational study based on prospectively collected data obtained from institutional cardiac surgery datasets of 3 high-volume specialist UK centers (Bristol, Papworth, and Southampton). The study was conducted in accordance with the principles of the Declaration of Helsinki. Institutional board approval was obtained for the study, and patient consent was waived.

Between January 2001 and October 2015, 252 octogenarians underwent mitral valve surgery. All the purely endocarditis, rheumatic, or ischemic cases were excluded to prevent selection bias. The final cohort consisted of 247 patients with degenerative MR (Figure E1 shows the distribution and type of surgery over the years). All patients were approached through a median sternotomy. Risk scoring has been calculated using the logistic European System for Cardiac Operative Risk Evaluation (euroSCORE). Degenerative disease was defined as single- or multi-segment prolapse due to chordal elongation or rupture. Emergency surgery was defined as surgery carried out within 24 hours of unscheduled admission, including 
patients presenting with acute decompensation of chronic MR. Patient demographics are summarized in Table 1. Table E1 shows the surgical techniques adopted.

Left ventricular ejection fraction (LVEF) was classified into 3 groups: good (LVEF $\geq 50 \%$ ), moderate (LVEF $>30 \%$ and $<50 \%$ ), and poor $(\mathrm{LVEF}<30 \%)$. Patients were considered to have chronic obstructive pulmonary disease (COPD) if they had any of the following conditions: longterm use of bronchodilators or steroids for lung disease before admission; outpatient visits including a diagnosis of COPD on 2 occasions or a previous inpatient stay with a discharge diagnosis of COPD; and preoperative lung function test with evidence of obstructive pattern. Patients were considered to have diabetes if they had any of the following conditions: receipt of insulin or oral hypoglycemic medications before admission; outpatient visits including a diagnosis of diabetes mellitus on 2 occasions; or a previous inpatient stay with a discharge diagnosis of diabetes mellitus.

\section{End Points}

The primary end points in the MiSO study were early mortality, defined as death due to all causes within 30 days from the day of surgery, and longterm survival. Secondary outcomes included new acute kidney injury (AKI) requiring dialysis, evidence of postoperative stroke (defined as clinical and radiologic evidence of a new postoperative cerebrovascular event), return to the operating room for cardiac causes, and sternal wound infection categorized in superficial (involving the skin, subcutaneous tissue, and pectoralis fascia only) and deep (involving sternal bone or mediastinal structures). Moreover, a composite outcome of death at 30 days or AKI with dialysis or postoperative cerebrovascular accident was considered for a multiple logistic regression analysis, designed to identify independent risk factors affecting early outcomes.
Data regarding long-term survival have been derived from our clinical dataset linked to the Office for National Statistics individually collected on October 31, 2015. The completeness for survival data was $100 \%$.

\section{Statistical Analysis}

Data are presented as mean \pm 1 standard deviation for numeric continuous variables and as per total number and percentages for categoric variables. The numeric variables were tested for normality with the ShapiroWilk test. Comparison between numeric variables has been conducted with the Student $t$ test for normally distributed variables or the MannWhitney $U$ test for not normally distributed variables. Inference on categoric variable has been done using the chi-square or Fisher exact test. To identify the predictors of composite outcome, a multivariable logistic regression model was developed: The initial model included those variables that had a $P$ value less than .25 with univariable analysis (age, previous cardiac surgery, intra-aortic balloon pump [IABP] use, emergency, logistic euroSCORE, concomitant coronary artery bypass grafting, reduced LVEF, and surgical technique): The final model was obtained by stepwise backward approach selecting for Akaike information criteria. Survival analysis was conducted using Kaplan-Meier methods and logrank test. A Cox proportional hazard model was designed to identify independent factors affecting long-term survival. To estimate the predicting ability of logistic euroSCORE on 30-day mortality, we used receiver operating characteristics curve analysis. The area under the curve was estimated for observed euroSCORE and the predicted values by fitting regression model. Missing values were screened before analysis: Every variable with more than $5 \%$ of missing value was eliminated from the final dataset. The remaining variables (Table E2) were imputed using simple imputation methods. The statistical analysis was conducted with $\mathrm{R}$

TABLE 1. Preoperative characteristics

\begin{tabular}{|c|c|c|c|c|}
\hline \multirow[b]{2}{*}{ Characteristic } & \multicolumn{4}{|c|}{ Surgical technique } \\
\hline & Overall (247) & Repair (150) & Replacement (97) & $\overline{P \text { value }}$ \\
\hline Age, y & $82.8 \pm 2.3$ & $82.9 \pm 2.3$ & $82.6 \pm 2.5$ & .12 \\
\hline Female gender & $108(43.7)$ & $62(41.3)$ & $46(47.4)$ & .41 \\
\hline BMI, $\mathrm{kg} / \mathrm{m}^{2}$ & $24.3 \pm 3.2$ & $24.3 \pm 3.6$ & $24.4 \pm 4.3$ & .89 \\
\hline $\begin{array}{l}\text { LVEF } \\
\text { Good }(\geq 50 \%) \\
\text { Moderate impairment }(\geq 30 \% \text { and }<50 \%) \\
\text { Severe impairment }(<30 \%)\end{array}$ & $\begin{array}{l}168(68) \\
64(25.9) \\
15(6.1)\end{array}$ & $\begin{aligned} 102 & (68) \\
38 & (25.3) \\
10 & (6.7)\end{aligned}$ & $\begin{array}{l}66(68) \\
26(25.3) \\
5(6.7)\end{array}$ & .87 \\
\hline Preoperative AF & $113(45.7)$ & $79(52.6)$ & $34(35.1)$ & $<.01$ \\
\hline Diabetes & $13(5.3)$ & $8(5.3)$ & $5(5.1)$ & 1 \\
\hline Hypertension & $133(53.8)$ & $80(53.3)$ & $53(54.6)$ & .94 \\
\hline COPD & $32(13)$ & $16(10.7)$ & $16(16.5)$ & .98 \\
\hline Smoking history & $113(45.7)$ & $71(47.3)$ & $42(43.3)$ & .62 \\
\hline Previous MI & $31(12.6)$ & $17(11.2)$ & $14(14.4)$ & .76 \\
\hline Logistic euroSCORE & $11.5 \pm 13.4$ & $10.2 \pm 11.8$ & $13.7 \pm 15.2$ & .07 \\
\hline Previous CVA & $19(7.7)$ & $11(7.3)$ & $8(8.2)$ & .98 \\
\hline NYHA III/IV & $180(72.9)$ & $106(70.6)$ & $74(76.3)$ & .4 \\
\hline Previous cardiac surgery & $17(6.9)$ & $6(4)$ & $11(11.3)$ & .04 \\
\hline Emergency & $6(2.4)$ & $2(1.3)$ & $4(4.1)$ & .21 \\
\hline Urgency & $34(13.8)$ & $23(15.3)$ & $11(11.3)$ & .37 \\
\hline
\end{tabular}

BMI, Body mass index; $L V E F$, left ventricular ejection fraction; $A F$, atrial fibrillation; COPD, chronic obstructive pulmonary disease; $M I$, myocardial infarction; euroSCORE, European System for Cardiac Operative Risk Evaluation; CVA, cerebrovascular accident; NYHA, New York Heart Association. 
TABLE 2. Operative characteristics and postoperative outcomes

\begin{tabular}{|c|c|c|c|c|}
\hline \multirow[b]{2}{*}{ Characteristic } & \multicolumn{4}{|c|}{ Surgical technique } \\
\hline & Overall (247) & Repair (150) & Replacement (97) & $P$ value \\
\hline CPB time (min) & $133.5 \pm 52.2$ & $128.9 \pm 47.5$ & $140.5 \pm 58.3$ & .21 \\
\hline Crossclamp time (min) & $95.9 \pm 38$ & $91.1 \pm 32.8$ & $103.3 \pm 44$ & .06 \\
\hline \multicolumn{5}{|l|}{ Concomitant procedures } \\
\hline CABG & $88(35.6)$ & $55(36.6)$ & $33(34)$ & .77 \\
\hline AVR & $53(21.5)$ & $27(18)$ & $26(26.8)$ & .14 \\
\hline $\mathrm{TV}$ & 47 (19) & $30(20)$ & $17(17.5)$ & .75 \\
\hline AF ablation & $19(7.7)$ & $17(11.3)$ & $2(2.1)$ & .02 \\
\hline 30-d mortality & $25(13.8)$ & $7(4.7)$ & $18(18.6)$ & $<.01$ \\
\hline CVA & $6(2.4)$ & $3(2)$ & $3(3.1)$ & .9 \\
\hline AKI (dialysis) & $23(9.3)$ & $10(6.7)$ & $13(13.4)$ & .12 \\
\hline Sternal wound infection & $37(15.2)$ & $18(12)$ & $19(20.4)$ & .11 \\
\hline Superficial & $31(12.6)$ & $15(10)$ & $16(16.5)$ & .17 \\
\hline Deep & $6(2.4)$ & $3(2)$ & $3(3.1)$ & .67 \\
\hline Return to operating room & $16(6.5)$ & $7(4.7)$ & $9(9.2)$ & .24 \\
\hline Postoperative length of stay (d) & $13.6 \pm 11.9$ & $14.1 \pm 9.5$ & $12.7 \pm 14.7$ & $<.01$ \\
\hline Composite outcome (death at $30 \mathrm{~d}, \mathrm{AKI}, \mathrm{CVA}$ ) & $41(16.6)$ & $16(10.6)$ & $25(25.7)$ & $<.01$ \\
\hline
\end{tabular}

$C P B$, Cardiopulmonary bypass; $C A B G$, coronary artery bypass grafting; $A V R$, aortic valve replacement; $T V$, tricuspid valve; $A F$, atrial fibrillation; $C V A$, cerebrovascular accident; $A K I$, acute kidney injury.

statistical software (R version 3.1.2 [2014-10-31] — "Pumpkin Helmet"; R Foundation for Statistical Computing, Vienna, Austria).

\section{RESULTS}

A total of 150 patients $(60.7 \%)$ underwent $\mathrm{MVr}$, and 97 patients $(39.3 \%)$ underwent MVR. The median follow-up was 2.9 years (minimum 0, maximum 14 years); mean follow-up was $41.4 \pm 35.6$ months. The distributions of baseline patient characteristics for the overall population are presented in Table 1. There were no significant differences in terms of age, body mass index (BMI), and other preoperative comorbidities between the 2 groups. The only significant differences were previous cardiac surgery (redo) $(4 \%$ vs $11.3 \%, P=.04)$ and preoperative atrial fibrillation $(52.6 \%$ vs $35.1 \%, P<.01)$ for the MVr and MVR groups, respectively. The New York Heart Association class distribution was similar in the 2 groups (Table 1). Patient operative risk, as estimated by the logistic euroSCORE, was lower in the MVr group (10.2 \pm 11.8 vs $13.7 \pm 15.2$ in MVR), although this difference was not statistically significant $(P=.07)$. No difference was found between groups for duration of cardiopulmonary bypass and aortic crossclamp times (Table 1). Associated procedures included 88 coronary artery bypass graftings (35.6\%), 53 aortic valve procedures $(21.5 \%), 47$ tricuspid valve procedures $(19 \%)$, and $19(7.7 \%)$ atrial fibrillation ablation procedures. Operative characteristics and postoperative outcomes are summarized in Table 2. The 30-day mortality for the whole cohort was $13.8 \%$ ( $\mathrm{MVr}$
$4.7 \%$ vs MVR $18.6 \% ; P<.01)$. No differences were found in terms of postoperative cerebrovascular accident $(\mathrm{MVr}$ $2 \%$ vs MVR $3.1 \% ; P=.9)$ and AKI requiring dialysis $(6.7 \%$ vs $13.4 \% ; P=.12)$. The overall incidence of sternal wound infection was not different between the 2 groups $(12 \%$ vs $20.4 \% ; P=.11)$. The deep sternal wound infection rate was not different $(2 \%$ vs $3.1 \%, P=.67)$. The length of stay in hospital after the surgery was found to be significantly longer in the $\mathrm{MVr}$ group $(14.1 \pm 9.5$ days vs $12.7 \pm 14.7$ days in MVR; $P<.01)$.

In the subgroup of patients who underwent a redo operation, the 30 -day mortality rate was $16.7 \%$ in the repair group versus $18.2 \%$ in the replacement group $(P=.9)$.

The final model logistic regression multivariable analysis (Table 3) for the short-term composite outcome showed that previous cardiac surgery (odds ratio [OR], 4.47; 95\%

TABLE 3. Multivariable logistic regression model for predictors of short-term composite outcome (death at 30 days, acute kidney injury, and cerebrovascular accident)

\begin{tabular}{lcc}
\hline \multicolumn{1}{c}{ Predictor } & OR $(\mathbf{9 5} \% \mathbf{C I})$ & $\boldsymbol{P}$ value \\
\hline Previous cardiac surgery & $4.47(1.37-17.46)$ & .02 \\
IABP use & $4.77(1.67-15.79)$ & $<.01$ \\
Reduced LVEF & $1.73(0.88-3.43)$ & .11 \\
MVR & $7.7(4.04-14.9)$ & $<.01$ \\
\hline
\end{tabular}

$O R$, Odds ratio; $C I$, confidence interval; $I A B P$, intra-aortic balloon pump; $L V E F$, left ventricular ejection fraction; $M V R$, mitral valve replacement. 
TABLE 4. Cox proportional hazard ratio multivariable model for predictor affecting long-term mortality*

\begin{tabular}{lcc}
\hline \multicolumn{1}{c}{ Predictor } & HR $(\mathbf{9 5} \% \mathbf{C I})$ & $\boldsymbol{P}$ value \\
\hline BMI & $0.94(0.89-1.01)$ & .09 \\
MVR & $1.88(1.22-2.89)$ & $<.01$ \\
IABP use & $2.54(1.26-5.13)$ & $<.01$ \\
Reduced LVEF & $1.09(0.42-2.82)$ & .84 \\
\hline
\end{tabular}

$H R$, Hazard ratio; $C I$, confidence interval; $B M I$, body mass index; $M V R$, mitral valve replacement; $I A B P$, intra-aortic balloon pump; $L V E F$, left ventricular ejection fraction. ${ }^{*}$ Gender has been included as stratum variable.

confidence interval $[\mathrm{CI}], 1.37-17.46 ; P=.02)$, IABP use (OR, 4.77; 95\% CI, 1.67-15.79; $P<.01$ ), and MVR (OR, $7.7 ; 95 \%$ CI, 4.04-14.9; $P<.01$ ) were independent negative predictors.

The Cox proportional hazard model results (Table 4) showed MVR (hazard ratio [HR], 2.16; 95\% CI, 1.42-3.3; $P<.01)$ and IABP use (HR, 2.67; 95\% CI, 1.52-4.7; $P<.01)$ to be independent predictor factors affecting long-term survival. BMI was found to be a protective factor (HR, 0.95; 95\% CI, 0.89-1.00; $P=.06$ ).

Overall survival for the entire cohort at 1,5 , and 10 years was $82.4 \%(95 \% \mathrm{CI}, 77.8-87.3), 63.7 \%$ (95\% CI, 57.071.2), and $45.5 \%$ (95\% CI, 36.0-57.5): $\mathrm{MVr}$ versus MVR: $89.9 \%$ (95\% CI, 85.2-94.9) versus $70.7 \%$ (95\% CI, 62.1-80.5) at 1 year, $69.6 \%$ (95\% CI, 61.2-79.1) versus $54.0 \%(95 \% \mathrm{CI}, 43.5-67.1)$ at 5 years, and $51.8 \%(95 \%$ CI, 39.4-68.2) versus $35.5 \%(95 \%$ CI, 22.9-55.1) at 10 years, respectively $(P<.01)$ (Figures 1 and 2). Logistic euroSCORE was unable to predict early and late mortality (area under the curve, 50.7\%) (Figures 3 and 4).

\section{DISCUSSION}

In the MiSO study, we found that in octogenarians, $\mathrm{MVr}$ for degenerative disease is associated with good early outcomes and late survival. MVR is still associated with significant mortality. Furthermore, previous cardiac surgery and the use of perioperative IABP are associated with decreased long-term survival, and increased BMI seems to be protective. Logistic euroSCORE does not seem to effectively predict early outcome in this group of patients.

The last 2 decades have seen a growing proportion of octogenarian patients being referred for mitral valve surgery. ${ }^{1-4}$ This increasing demand is related to prolonged life expectancy and reported better outcome of mitral surgery in this population. ${ }^{3-11}$ However, approximately half of patients affected by severe MR are not referred for surgery mainly because of their advanced age, comorbidities, and left ventricular dysfunction, ${ }^{2,4}$ and in specialized centers there seems to be an increasing trend to treat elderly patients with percutaneous procedures. ${ }^{27,28}$ This reflects the misperception that mitral valve surgery is associated with prohibitively high early mortality in this age group. The decision for surgery is complex; several elements, such as the lack of correspondence between physiologic and chronologic age, the quality of life, and the risk-benefit ratio, should be taken into account before confirming a surgical indication. This article, analyzing the early and long-term outcomes of 247 octogenarians undergoing conventional mitral valve surgery, is aimed at assisting in making an informed decision for the patients and the clinicians regarding surgery or catheter-based mitral intervention in octogenarian patients with degenerative mitral valve disease.

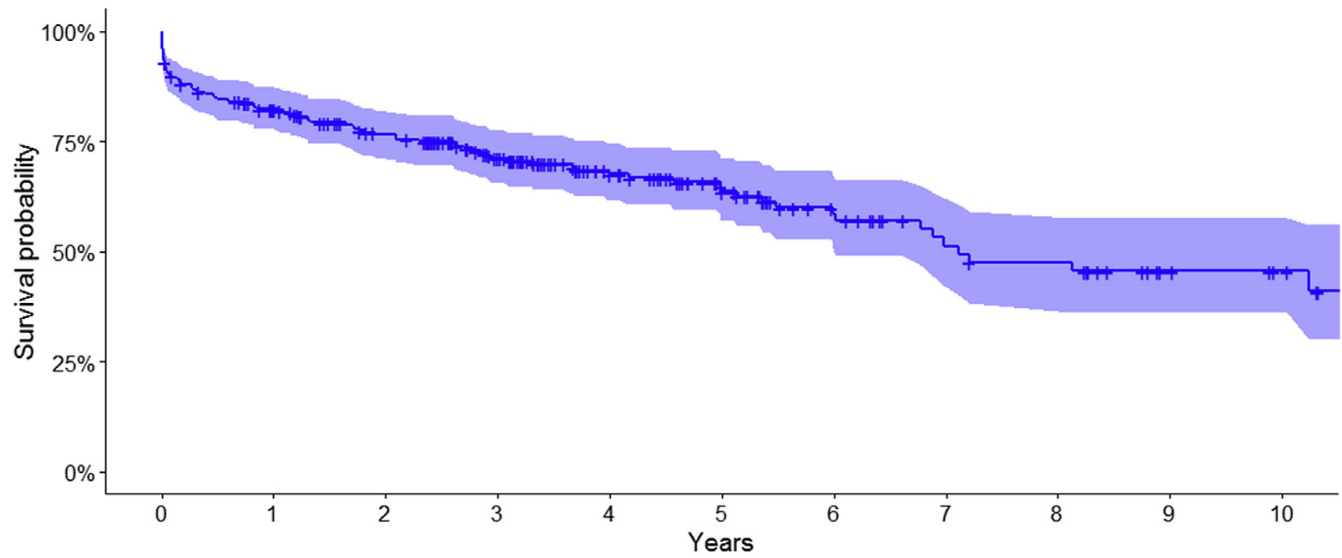

Number of patients at risk

\begin{tabular}{|c|c|c|c|c|c|c|c|c|c|c|c|}
\hline \multirow{3}{*}{$\frac{\mathbb{\pi}}{\frac{\pi}{\mathbb{*}}}$} & \\
\hline & 247 & 190 & 160 & 122 & 82 & 58 & 39 & 27 & 24 & 14 & 11 \\
\hline & 0 & 1 & 2 & 3 & 4 & $\begin{array}{c}5 \\
\text { Years }\end{array}$ & 6 & 7 & 8 & 9 & 10 \\
\hline
\end{tabular}

FIGURE 1. Kaplan-Meier survival curve for the overall surgical population. 


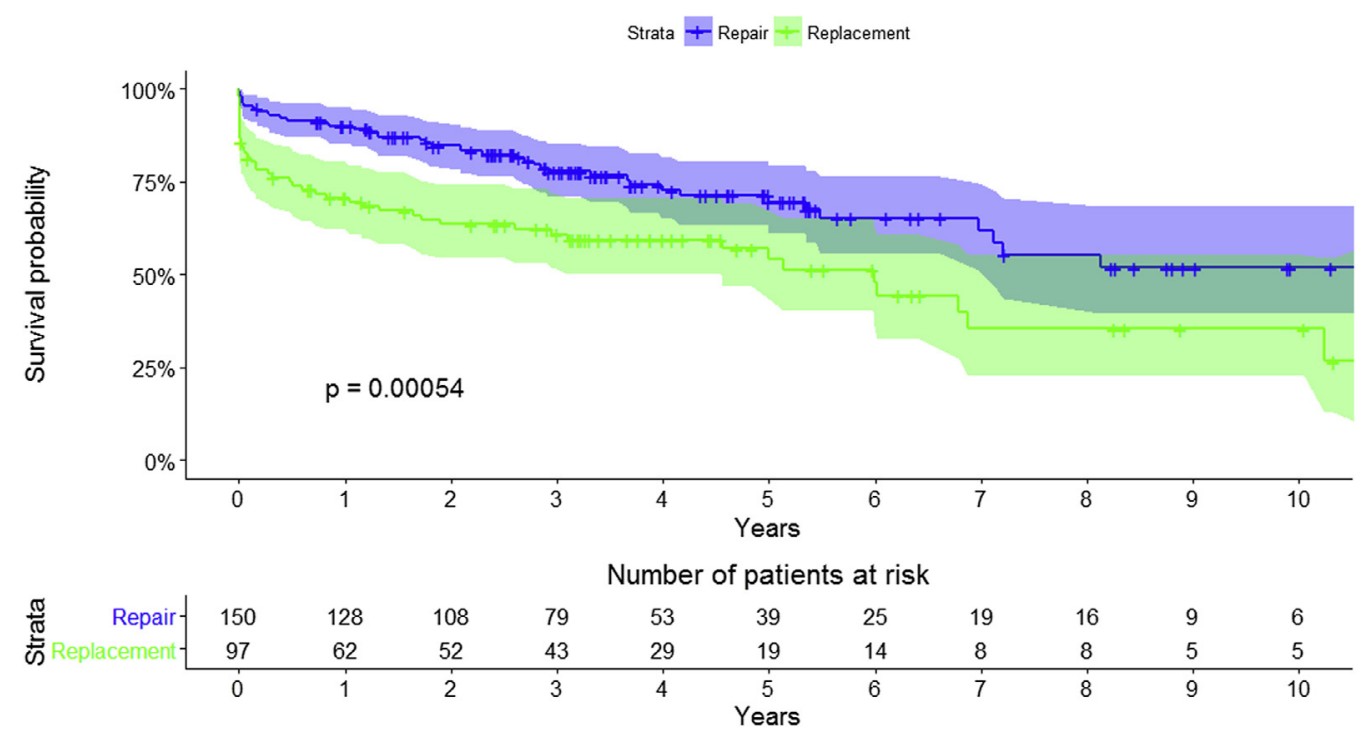

FIGURE 2. Kaplan-Meier survival curves between the 2 groups (raw data).

The results of our study suggest that being octogenarians does not necessarily implicate higher surgical risk. With the help of receiver operating characteristics analysis, we have confirmed the suspicion that the logistic euroSCORE does not provide a valid means of determining the predicted mortality in this unique subset of patients, and there is a need to generate a mitral score on the basis of large multicenter mitral valve surgery registries, especially for very highrisk patients.

In our study, 30-day mortality for the whole cohort was $13.8 \%$ (MVr $4.7 \%$ vs MVR $18.6 \% ; P<.01$ ). This result is similar to reports by other series; the operative mortality in a cohort of 2700 octogenarian patients undergoing MVR between 1997 and 2000 from the Society of Thoracic Surgeons National Cardiac Database was $16.9 \%{ }^{13}$ In smaller single-center studies, operative mortality has ranged from $15 \%$ to $20 \%,{ }^{13,14,17,19,20,22}$ which is similar to what we observed in our overall cohort. However, lower operative mortality has been reported in elderly patients with nonischemic MR undergoing isolated mitral surgery similar to that reported in this article. Moreover, with an overall survival of $63.7 \%$ at 5 years and 45.5 at 10 years, we showed that this surgery has important long-term benefits even in octogenarians, with a substantial superiority of $\mathrm{MVr}$ compared with MVR. It has been shown that MVr is preferred over MVR to treat MR due to degenerative mitral

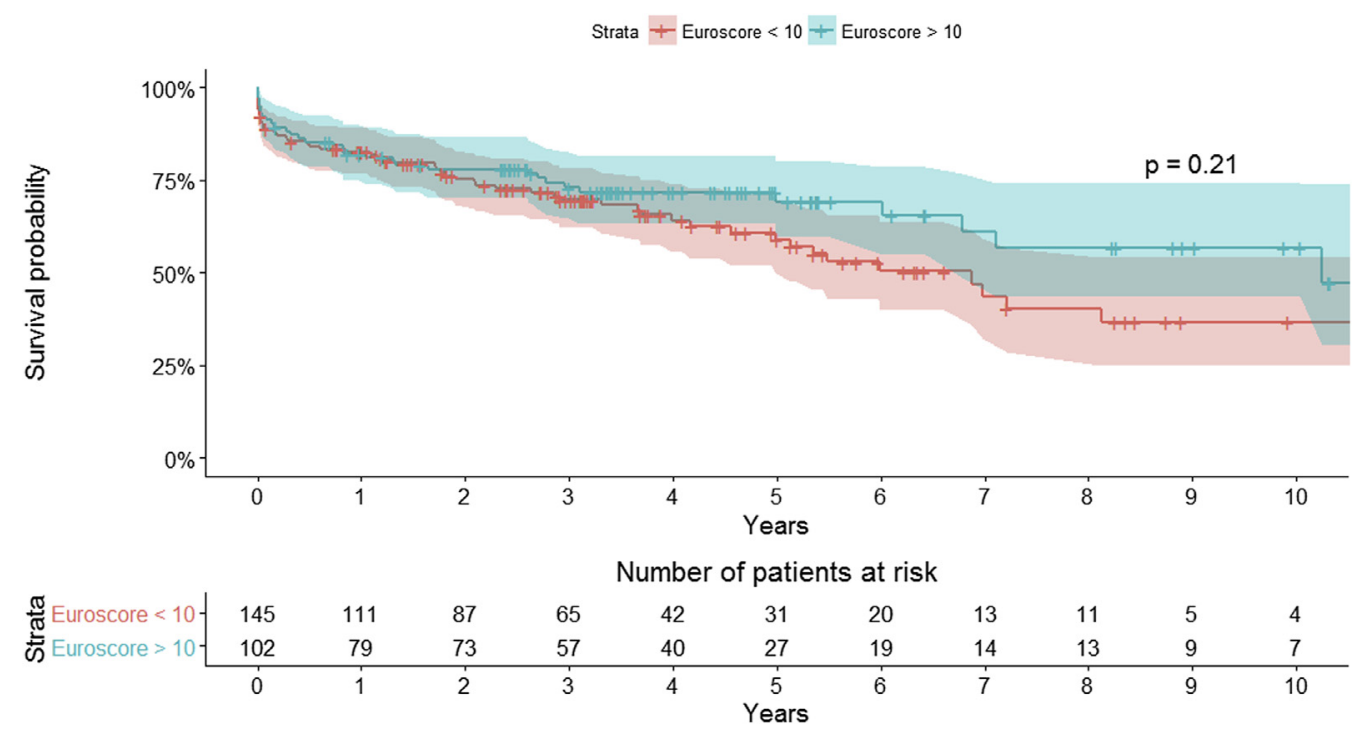

FIGURE 3. Impact of euroSCORE on survival: Kaplan-Meier survival curves. euroSCORE, European System for Cardiac Operative Risk Evaluation. 


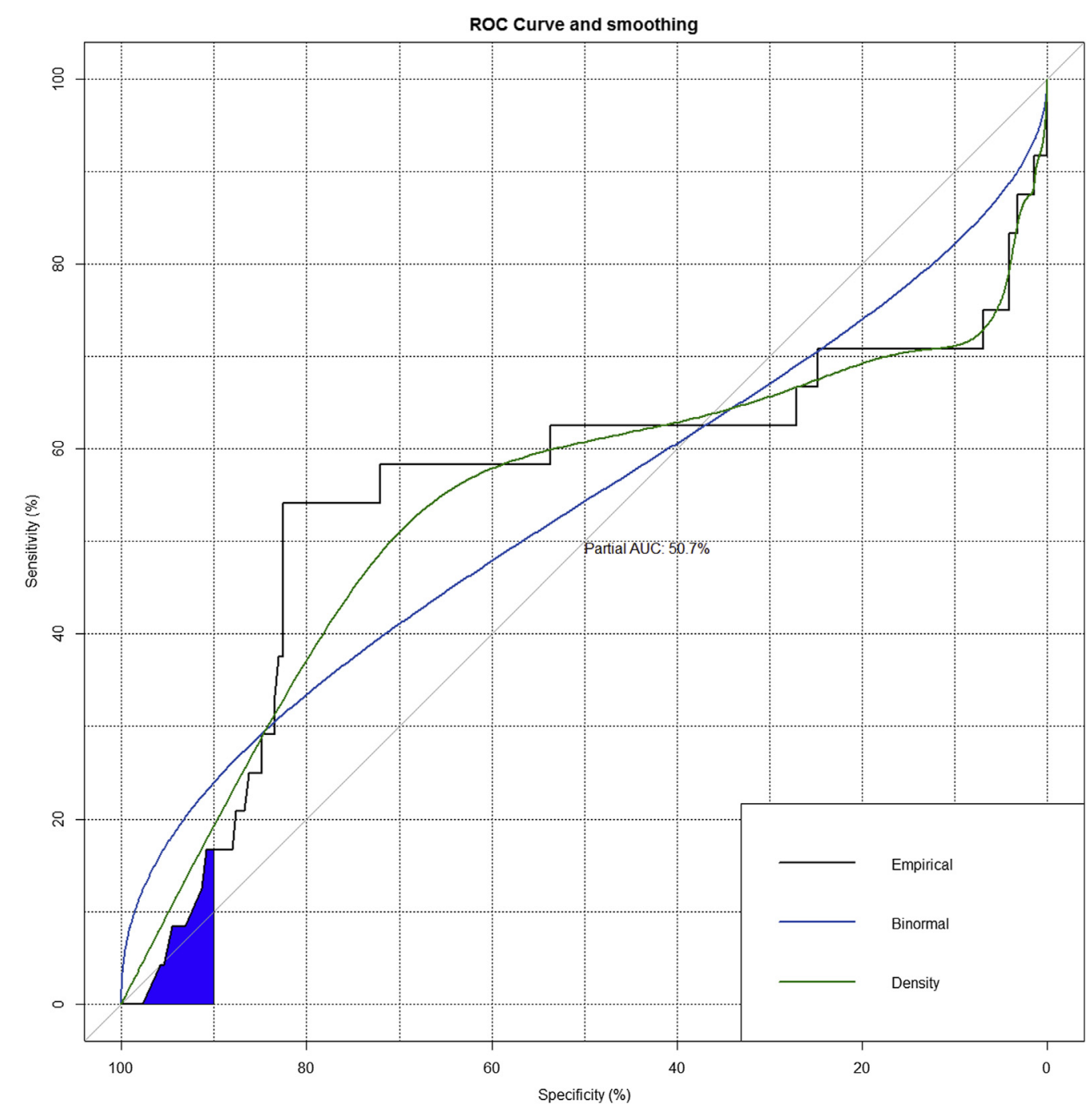

FIGURE 4. Predictive value of euroSCORE (receiver operating characteristics $[R O C]$ curve). $A U C$, Area under the curve.

valve disease with improved short- and long-term survivals. $^{5-11}$ Initially, $\mathrm{MVr}$ was considered to be an unnecessary procedure in elderly subjects; moreover, there were concerns that fragile tissues and valvular calcification were more likely to preclude satisfactory valve repair in older patients. ${ }^{14}$ However, with increasing skill and understanding of mitral disease, the repair rate, especially in expert hands in high-volume centers, has continued to grow in the last few years. ${ }^{12-26}$ Our study confirms this trend, with an increasing ratio of MVr to MVR over time in octogenarians without significant cardiopulmonary bypass time difference between the 2 techniques. In the octogenarian population, a survival of approximately $70 \%$ at 5 years and approximately $52 \%$ at 10 years after $\mathrm{MVr}$ for degenerative MR in our highvolume multicenter experience strengthens the case to recommend $\mathrm{MVr}$ as the gold standard for degenerative MR in octogenarians.
An increasingly emerging alternative in treating mitral valve disease is represented by the minimally invasive approach through right minithoracotomy. Faster recovery and reduced pain make this approach a valid and reliable substitute to classic median sternotomy. ${ }^{33-38}$ There is a large body of evidence in the literature showing that minimally invasive mitral valve surgery is not inferior to the conventional surgical approach using a full sternotomy, especially with regard to operative results and long-term survival. ${ }^{34,35}$ This seems to be valid even in octogenarians, with some authors reporting a trend toward a lower operative mortality, rate of transfusion, and an overall faster recovery with shorter postoperative hospital stays for the minimally invasive approach. ${ }^{36-38}$

Transcatheter mitral technologies have developed as a viable option to treat high-risk and inoperable patients with severe MR, having shown promising early outcomes, especially in terms of procedural safety. ${ }^{27-32}$ Buzzatti and 
colleagues ${ }^{30}$ recently published their results comparing the outcomes of patients aged 80 years or more, affected by isolated degenerative MR, who underwent isolated transcatheter $(\mathrm{n}=25)$ or surgical $(\mathrm{n}=35,29$ repairs and 6 replacements) mitral intervention. Follow-up overall mortality was higher in the MitraClip group (MitraClip System, Abbott Vascular, Inc) than in the surgery group, although after the first 30 days, only 1 of 5 deaths observed in the MitraClip group was cardiac related. Regardless of survival, as confirmed by Lim and colleagues ${ }^{31}$ in a population of patients with prohibitive-risk degenerative MV, the MitraClip can make octogenarians with severe degenerative MR feel better, reducing their symptoms and improving their quality of life. A recent meta-analysis by Takagi and colleagues ${ }^{32}$ comparing the MitraClip with surgical repair for MR in all age groups showed similar early and late mortality survival between the 2 procedures, despite higher-risk profiles in the percutaneous intervention group.

An interesting finding of this study is represented by the protective effect of BMI. There is increasing evidence regarding the protective role of obesity in cardiac surgery. ${ }^{39,40}$ In an apparent paradox, morbidity and mortality are lower in obese patients undergoing cardiac surgery, although the nature of this association is unclear. Even in our subgroup of octogenarians undergoing mitral valve surgery, this protective effect was confirmed.

\section{Study Limitations}

This study is retrospective and multicenter, and thus has the associated limitations of potential heterogeneity. It includes a small cohort of patients, and because of the logistics, it was not possible to achieve long-term clinical echocardiographic follow-up for all the 3 centers. Moreover it lacks data on the indication for repair or replacement at the time of surgery and therefore is unable to correctly delineate factors affecting surgical selection, and also does not provide information on the long-term cause of death. The absence of a nonsurgical group (ie, medical treatment or transcatheter treatment) is another important limitation.

\section{CONCLUSIONS}

In the MiSO study involving high-volume mitral specialist centers, we have demonstrated that in octogenarians, $\mathrm{MVr}$ for degenerative disease is associated with very good survival and should be considered the gold standard. Predictors of poor long-term survival include previous cardiac surgery and the need for perioperative IABP. Larger international multicenter registries are required to create a powerful scoring system in guiding decision-making in such a high-risk subgroup because the logistic euroSCORE does not accurately reflect the exact risk profile of these patients.

\section{Conflict of Interest Statement}

Authors have nothing to disclose with regard to commercial support.

\section{References}

1. Singh JP, Evans JC, Levy D, Larson MG, Freed LA, Fuller DL, et al. Prevalence and clinical determinants of mitral, tricuspid, and aortic regurgitation (the Framingham Heart Study). Am J Cardiol. 1999;83:897-902.

2. Mirabel M, Iung B, Baron G, Messika-Zeitoun D, Detaint D, Vanoverschelde JL, et al. What are the characteristics of patients with severe, symptomatic, mitral regurgitation who are denied surgery? Eur Heart J. 2007;28:1358-65.

3. Fremes SE, Goldman BS, Ivanov J, Weisel RD, David TE, Salerno T. Valvular surgery in the elderly. Circulation. 1989;80:177-9.

4. Collart F, Feier H, Kerbaul F, Mouly-Bandini A, Riberi A, Mesana TG, et al. Valvular surgery in octogenarians: operative risks factors, evaluation of EuroSCORE and long term results. Eur J Cardiothorac Surg. 2005;27:276-80.

5. Gillinov AM, Cosgrove DM, Blackstone EH, Diaz R, Arnold JH, Lytle BW, et al Durability of mitral valve repair for degenerative disease. J Thorac Cardiovasc Surg. 1998;116:734-43.

6. Filsoufi F, Carpentier A. Principles of reconstructive surgery in degenerative mitral valve disease. Semin Thorac Cardiovasc Surg. 2007;19:103-10.

7. Braunberger E, Deloche A, Berrebi A, Abdallah F, Celestin JA, Meimoun P, et al Very long-term results (more than 20 years) of valve repair with Carpentier's techniques in nonrheumatic mitral valve insufficiency. Circulation. 2001; 104(12 Suppl 1):I8-11

8. Anyanwu AC, Itagaki S, Chikwe J, El-Eshmawi A, Adams DH. A complexity scoring system for degenerative mitral valve repair. J Thorac Cardiovasc Surg. 2016;151:1661-70

9. Enriquez-Sarano M, Schaff HV, Orszulak TA, Tajik AJ, Bailey KR, Frye RL. Valve repair improves the outcome of surgery for mitral regurgitation. A multivariate analysis. Circulation. 1995;91:1022-8.

10. Suri RM, Schaff HV, Dearani JA, Sundt TM, Daly RC, Mullany CJ, et al. Survival advantage and improved durability of mitral repair for leaflet prolapse subsets in the current era. Ann Thorac Surg. 2006;82:819-26.

11. Piazza N, Onuma Y, de Jaegere P, Serruys PW. Guidelines for reporting mortality and morbidity after cardiac valve interventions - need for a reappraisal? Ann Thorac Surg. 2009;87:357-8.

12. Nloga J, Hénaine R, Vergnat M, Wautot F, Desebbe O, Robin J, et al. Mitral valve surgery in octogenarians: should we fight for repair? A survival and quality-oflife assessment. Eur J Cardiothorac Surg. 2011;39:875-80.

13. Mehta RH, Eagle KA, Coombs LP, Peterson ED, Edwards FH, Pagani FD, et al Influence of age on outcomes in patients undergoing mitral valve replacement. Ann Thorac Surg. 2002;74:1459-67.

14. Chikwe J, Goldstone AB, Passage J, Anyanwu AC, Seeburger J, Castillo JG, et al. A propensity score-adjusted retrospective comparison of early and mid-term results of mitral valve repair versus replacement in octogenarians. Eur Heart J 2011;32:618-26.

15. Grossi EA, Zakow PK, Sussman M, Galloway AC, Delianides J, Baumann G, et al. Late results of mitral valve reconstruction in the elderly. Ann Thorac Surg. 2000;70:1224-6.

16. Jebara VA, Dervanian P, Acar C, Grare P, Mihaileanu S, Chauvaud S, et al. Mitral valve repair using Carpentier techniques in patients more than 70 years old. Early and late results. Circulation. 1992;86(5 Suppl):II53-9.

17. Thourani VH, Weintraub WS, Guyton RA, Jones EL, Williams WH, Elkabbani S, et al. Outcomes and long-term survival for patients undergoing mitral valve repair versus replacement: effect of age and concomitant coronary artery bypass grafting. Circulation. 2003;108:298-304.

18. Craver JM, Cohen C, Weintraub WS. Case-matched comparison of mitral valve replacement and repair. Ann Thorac Surg. 1990;49:964-9.

19. Alexander KP, Anstrom KJ, Muhlbaier LH, Grosswald RD, Smith PK, Jones RH, et al. Outcomes of cardiac surgery in patients $>$ or $=80$ years: results from the National Cardiovascular Network. J Am Coll Cardiol. 2000;35:731-8.

20. Ailawadi G, Swenson BR, Girotti ME, Gazoni LM, Peeler BB, Kern JA, et al. Is mitral valve repair superior to replacement in elderly patients? Ann Thorac Surg. 2008:86:77-85.

21. Goldsmith I, Lip GY, Kaukuntla H, Patel RL. Hospital morbidity and mortality and changes in quality of life following mitral valve surgery in the elderly J Heart Valve Dis. 1999;8:702-7.

22. Nagendran J, Norris C, Maitland A, Koshal A, Ross DB. Is mitral valve surgery safe in octogenarians? Eur J Cardiothorac Surg. 2005;28:83-7. 
23. Jokinen JJ, Hippelainen MJ, Pitkanen OA, Hartikainen JE. Mitral valve replacement versus repair: propensity-adjusted survival and quality-of life analysis. Ann Thorac Surg. 2007;84:451-8.

24. Detaint D, Sundt TM, Nkomo VT, Scott CG, Tajik AJ, Schaff HV, et al. Surgical correction of mitral regurgitation in the elderly: outcomes and recent improvements. Circulation. 2006;114:265-72.

25. Gogbashian A, Sepic J, Soltesz EG, Nascimben L, Cohn LH. Operative and longterm survival of elderly is significantly improved by mitral valve repair. Am Heart J. 2006;151:1325-33.

26. Vassileva CM, McNeely C, Spertus J, Markwell S, Hazelrigg S. Hospital volume, mitral repair rates, and mortality in mitral valve surgery in the elderly: an analysis of the US hospitals treating Medicare fee-for-service patients. J Thorac Cardiovasc Surg. 2015;149:762-8.

27. Testa L, Latib A, Montone RA, Bedogni F. Transcatheter mitral valve regurgitation treatment: state of the art and a glimpse to the future. J Thorac Cardiovasc Surg. 2016;152:319-27.

28. Woo YJ, Goldstone AB. The contemporary evolution of mitral valve surgery. $J$ Thorac Cardiovasc Surg. 2016;151:7-9.

29. Feldman T, Kar S, Elmariah S, Smart SC, Trento A, Siegel RJ, et al; EVEREST II Investigators. Randomized comparison of percutaneous repair and surgery for mitral regurgitation: 5-year results of EVEREST II. J Am Coll Cardiol. 2015; 66:2844-54

30. Buzzatti N, Maisano F, Latib A, Taramasso M, Denti P, La Canna G, et al. Comparison of outcomes of percutaneous MitraClip versus surgical repair or replacement for degenerative mitral regurgitation in octogenarians. Am J Cardiol. 2015; 115:487-92.

31. Lim DS, Reynolds MR, Feldman T, Kar S, Herrmann HC, Wang A, et al Improved functional status and quality of life in prohibitive surgical risk patients with degenerative mitral regurgitation after transcatheter mitral valve repair. $J$ Am Coll Cardiol. 2014;64:182-92.

32. Takagi H, Ando $\mathrm{T}$, Umemoto $\mathrm{T}$. ALICE (All-Literature Investigation of Cardiovascular Evidence) Group. A review of comparative studies of MitraClip versus surgical repair for mitral regurgitation. Int J Cardiol. 2017;228:289-94.
33. Sündermann SH, Czerny M, Falk V. Open vs. minimally invasive mitral valve surgery: surgical technique, indications and results. Cardiovasc Eng Technol. 2015;6:160-6

34. Sündermann SH, Sromicki J, Rodriguez Cetina Biefer H, Seifert B, Holubec T, Falk V, et al. Mitral valve surgery: right lateral minithoracotomy or sternotomy? A systematic review and meta-analysis. J Thorac Cardiovasc Surg. 2014;148: 1989-95.

35. Miceli A, Murzi M, Canarutto D, Gilmanov D, Ferrarini M, Farneti PA, et al. Minimally invasive mitral valve repair through right minithoracotomy in the setting of degenerative mitral regurgitation: early outcomes and long-term follow-up. Ann Cardiothorac Surg. 2015;4:422-7.

36. Moscarelli M, Cerillo A, Athanasiou T, Farneti P, Bianchi G, Margaryan R, et al. Minimally invasive mitral valve surgery in high-risk patients: operating outside the boxplot. Interact Cardiovasc Thorac Surg. 2016;22: 756-61.

37. Seeburger J, Raschpichler M, Jens Garbade J, Piroze Davierwala PM, Pfannmueller B, Borger MA, et al. Minimally invasive mitral valve surgery in octogenarians - a brief report. Ann Cardiothorac Surg. 2013;2:765-7.

38. Holzhey DM, Shi W, Borger MA, Seeburger J, Garbade J, Pfannmüller B, et al. Minimally invasive versus sternotomy approach for mitral valve surgery in patients greater than 70 years old: a propensity-matched comparison. Ann Thorac Surg. 2011;91:401-5.

39. Mariscalco G, Woźniak MJ, Dawson AG, Serraino GF, Porter R, Nath M, et al. Body-mass index and mortality among adults undergoing cardiac surgery: a nationwide study with a systematic review and meta-analysis. Circulation. 2017; 135:850-63.

40. Johnson AP, Parlow JL, Whitehead M, Xu J, Rohland S, Milne B. Body mass index, outcomes, and mortality following cardiac surgery in Ontario, Canada. J Am Heart Assoc. 2015;4(7).

Key Words: mitral regurgitation, mitral valve, mitral valve surgery, multicenter, octogenarians

Readers who found these articles interesting may also like to read the following papers found in recent and future issues of our sister publications, Seminars in Thoracic and Cardiovascular Surgery and Operative Techniques in Thoracic and Cardiovascular Surgery!

\section{Adult: Mitral Valve}

ORIGINAL SUBMISSION: Assessment of Mitral Valve Repair With Exercise Echocardiography: Artificial Chordae vs Leaflet Resection Sigurdur Ragnarsson. Semin Thoracic Surg 2017: 25-32.

Editorial Commentary: The Dance of 2 Devils: Mitral Valve Repair and Functional Mitral Stenosis. Bobby Yanagawa. Semin Thoracic Surg 2017: 33-34. 


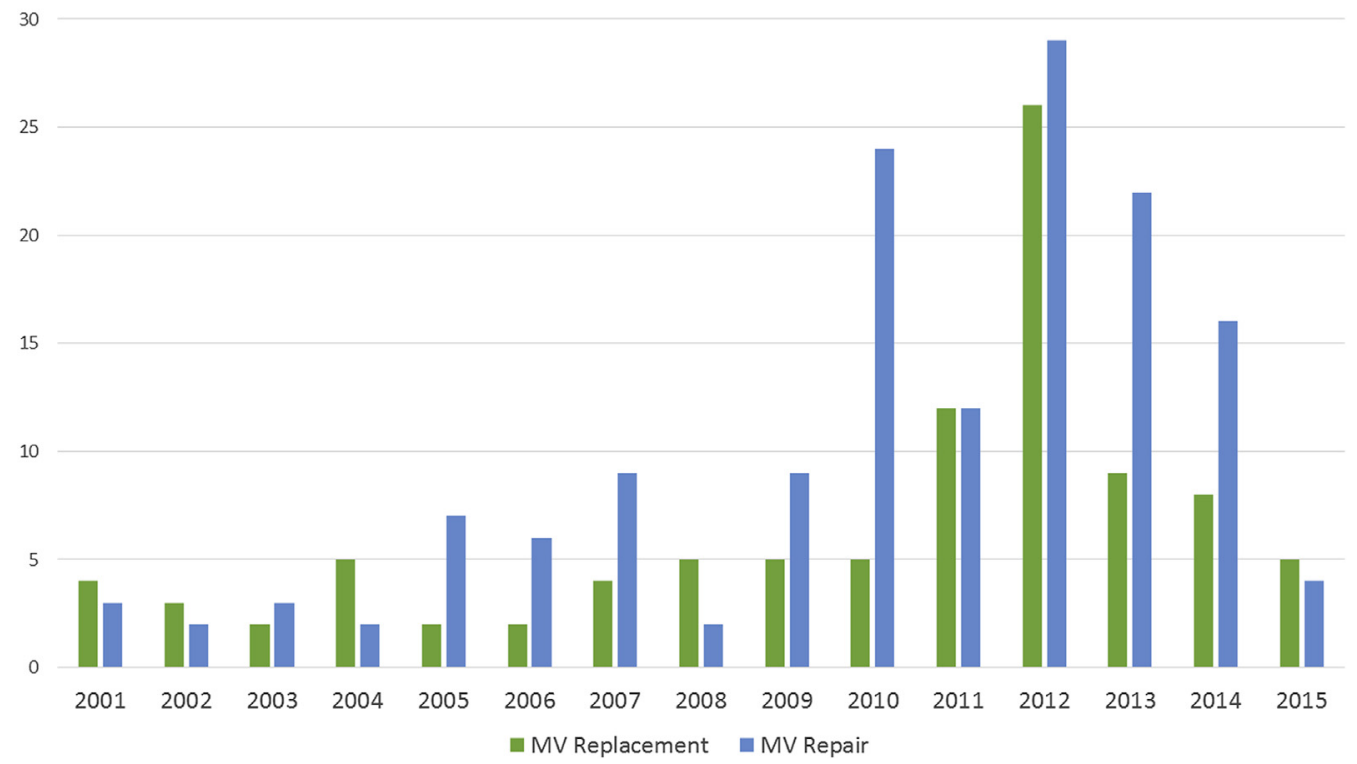

FIGURE E1. Distribution and type of mitral valve surgeries over the years. $M V$, Mitral valve.

TABLE E1. Surgical characteristics

\begin{tabular}{lcc}
\hline & \multicolumn{2}{c}{ Surgical technique } \\
\cline { 2 - 3 } Characteristic & Repair (150) & Replacement (97) \\
\hline Repair type* & $43(37.1)$ & NA \\
Leaflet resection & $116(100)$ & NA \\
Annuloplasty ring & $43(37.1)$ & NA \\
Neochordae & & \\
Replacement & NA & $10(10.3)$ \\
Mechanical & NA & $87(89.7)$ \\
Biological & & \\
Prostheses size & NA & 2 \\
23 mm & NA & 16 \\
25 mm & NA & 20 \\
27 mm & NA & 26 \\
29 mm & NA & 18 \\
$31 \mathrm{~mm}$ & NA & 15 \\
$33 \mathrm{~mm}$ & & \\
Procedures per center & 58 & 23 \\
Center A & 40 & 35 \\
Center B & 52 & 39 \\
Center C & & \\
\hline
\end{tabular}

$N A$, Not available. *Data available for 116 patients $(77.3 \%$ of the total). 
TABLE E2. Missing values distribution

\begin{tabular}{|c|c|c|}
\hline Characteristic & $\begin{array}{c}\text { Count of } \\
\text { missing values }\end{array}$ & $\begin{array}{c}\% \text { of missing } \\
\text { values }\end{array}$ \\
\hline Age, y & 0 & 0 \\
\hline Female gender & 0 & 0 \\
\hline BMI, $\mathrm{kg} / \mathrm{m}^{2}$ & 0 & 0 \\
\hline LVEF & 3 & 1.2 \\
\hline Preoperative rhythm & 0 & 0 \\
\hline Diabetes & 1 & 0.4 \\
\hline Hypertension & 1 & 0.4 \\
\hline COPD & 1 & 0.4 \\
\hline Smoking history & 1 & 0.4 \\
\hline Previous MI & 2 & 0.8 \\
\hline Logistic euroSCORE & 5 & 2 \\
\hline Previous CVA & 2 & 0.8 \\
\hline NYHA III/IV & 0 & 0 \\
\hline Previous cardiac surgery & 1 & 0.4 \\
\hline Operative urgency & 0 & 0 \\
\hline CPB time & 2 & 0.8 \\
\hline Crossclamp time & 2 & 0.8 \\
\hline Concomitant procedures & 1 & 0.8 \\
\hline 30-d mortality & 0 & 0 \\
\hline CVA & 4 & 1.6 \\
\hline AKI (dialysis) & 2 & 0.8 \\
\hline Sternal wound infection & 0 & 0 \\
\hline Return to operating room & 0 & 0 \\
\hline Postoperative length of stay (d) & 0 & 0 \\
\hline \multicolumn{3}{|c|}{$\begin{array}{l}B M I \text {, Body mass index; } L V E F \text {, left ventricular ejection fraction; COPD, chronic } \\
\text { obstructive pulmonary disease; } M I \text {, myocardial infarction; euroSCORE, European } \\
\text { System for Cardiac Operative Risk Evaluation; } C V A \text {, cerebrovascular accident; } \\
N Y H A \text {, New York Heart Association; } C P B \text {, cardiopulmonary bypass; } A K I \text {, acute kid- } \\
\text { ney injury. }\end{array}$} \\
\hline
\end{tabular}

